\title{
RELATÓRIO DE SUSTENTABILIDADE E DESEMPENHO DAS FIRMAS BRASILEIRAS DE CAPITAL ABERTO
}

\author{
SUSTAINABILITY REPORT AND PERFORMANCE OF \\ BRAZILIAN PUBLIC COMPANIES
}

\author{
DERMEVAL MARTINS BORGES JUNIOR \\ Universidade Federal de Uberlândia. Endereço: Av. João Naves de Ávila, \\ 2121 | Bloco: $1 F$ | Sala: $1 F-248$ |Campus Santa Mônica | 38400-902 | \\ Uberlândia/MG $\mid$ Brasil. \\ Dhttp://orcid.org/0000-0003-2279-449X \\ dermevaljr14@gmail.com
}

\section{RESUMO}

O objetivo deste trabalho foi analisar a associação entre a publicação do relatório de sustentabilidade e o desempenho das empresas abertas brasileiras. Foram coletados dados sobre a publicação do relatório de sustentabilidade das empresas abertas brasileiras listadas na bolsa de valores do Brasil (B3), bem como para variáveis relativas às características das firmas, a saber: desempenho, tamanho e alavancagem. A amostra do estudo contou com todas as empresas abertas brasileiras listadas na B3, exceto as financeiras, por suas especificidades contábeis, com dados disponíveis no período de 2012 a 2016, as quais totalizaram 1.889 observações. Dentre os resultados, observou-se que as empresas que publicam relatório de sustentabilidade possuem médias superiores para as medidas de desempenho, tamanho e alavancagem em relação às firmas que não publicam tal documento. Além disso, os coeficientes de correlação para as variáveis estudadas, dentre outros aspectos, indicaram uma associação positiva e estatisticamente significativa entre a publicação do relatório de sustentabilidade e o desempenho, tamanho da firma e alavancagem financeira.

Palavras-chave: Relatório de sustentabilidade. Disclosure socioambiental. Desempenho.

\section{ABSTRACT}

This study aims to analyze the association between the publication of the sustainability report and the performance of Brazilian public companies. Data were collected on the publication of the sustainability report from Brazilian companies listed on the Brazilian Stock Exchange (B3), as well as variables related to the characteristics of these companies, namely: performance, size and leverage. The study sample include all Brazilian public companies listed on B3 - except those of financial nature, due to their accounting specificities -, with data available in the period between 2012 and 2016, corresponding to 1,889 observations. This study shows that companies

Artigo apresentado no Encontro de Gestão e Negócios - EGEN da Universidade Federal de Uberlândia, em 31 de outubro de 2018.

Submissão em 01/11/2018. Revisão em 21/01/2019. Aceito em 15/02/2019. Publicado em 07/03/2019. 
that do publish sustainability reports have better results for performance, size and leverage compared to companies that do not. In addition, correlation coefficients for the variables studied hereunder indicated, among other aspects, a positive and statistically significant association between publication of sustainability report and performance, size and financial leverage.

Keywords: Sustainability report. Social and Environmental Management. Performance.

\section{INTRODUÇÃO}

As organizações são pressionadas por governos, clientes, entidades sociais, empregados, fornecedores, acionistas, entre outros stakeholders, a adotar práticas socialmente responsáveis e encorajadas a destinar recursos em investimentos relacionados à sustentabilidade corporativa. Nesse sentido, é comum encontrar firmas que aplicam recursos ou desenvolvem atividades relacionadas à responsabilidade socioambiental corporativa. Da mesma forma, existem organizações que resistem a essas demandas e argumentam que tais investimentos são incompatíveis com a maximização dos lucros e, por consequência, comprometem a geração de riqueza para os sócios (McWilliams \& Siegel, 2000).

O mercado financeiro também tem sofrido influência da preocupação geral com as questões socioambientais, uma vez que os investidores vêm optando por investir seus recursos nas empresas sustentáveis e socialmente responsáveis. Isso é o que se pode concluir com base no relatório emitido pelo European Sustainable Investment Forum (2014), no qual ficou demonstrado que os investimentos socialmente responsáveis cresceram significativamente na Europa de 2011 a 2013. No Brasil ainda não é possível saber com precisão sobre esses dados, pois não são realizados levantamentos a respeito, mas investimentos dessa natureza vêm se tornando uma tendência global. A lógica por trás disso é que as empresas sustentáveis estão mais qualificadas para lidar com questões econômicas, sociais e ambientais, e, por isso, tornam-se uma boa opção para investidores, uma vez que, em tese, possuem menor risco e geram valor no longo prazo.

Nesse contexto, é crescente o número de firmas que divulgam relatórios específicos com informações socioambientais. A partir de 2012, a bolsa de valores do Brasil (B3) passou a recomendar que as empresas listadas indicassem expressamente no seu respectivo formulário de referência se publicavam ou não relatórios de sustentabilidade (ou similares) e onde estes estariam disponíveis. Ademais, nos casos em que não eram publicados, as empresas deveriam explicar os motivos pelos quais não o faziam (diante do caráter voluntário, as firmas ainda poderiam não se manifestar). Em 2012, 45,31\% das empresas listadas publicaram o relatório de sustentabilidade ou explicaram o motivo da não publicação. Esse percentual cresceu nos anos seguintes, sendo 66,29\% em 2013, 71,17\% em 2014 e 71,65\% em 2015 (BM\&FBovespa, 2016).

Segundo Jones, Frost, Loftus e Van Der Laan (2007), a divulgação do relatório de sustentabilidade está associada a melhores indicadores de desempenho da firma por diversos motivos. Primeiramente, as empresas que historicamente apresentam bom desempenho possuem maior disponibilidade de recursos para despender em iniciativas voluntárias, dentre as quais, a publicação de relatórios de sustentabilidade. Além disso, outra possibilidade está fundamentada na eficiência de gestão, uma vez que empresas geridas eficientemente tendem a obter bom desempenho em diversas outras áreas além das questões econômico-financeiras, inclusive na divulgação socioambiental. Os autores ainda mencionam que as empresas preocupadas em divulgar relatórios de sustentabilidade normalmente são de setores com atividades que exercem forte impacto ambiental (e.g. indústria ou energia) ou social (e.g. bancos) e que sofrem pressão da sociedade nesse sentido, as quais tendem a apresentar alto desempenho econômico-financeiro.

Em contrapartida, há uma corrente teórica crítica em relação ao relatório de sustentabilidade, a qual contesta seus benefícios. Gray e Milne (2002) afirmam que não existe relatório de sustentabilidade em lugar algum do mundo, uma vez que é praticamente impossível 
definir com precisão o que seria uma empresa sustentável, bem como relatar sua sustentabilidade. Por sua vez, Michelon, Pilonato e Ricceri (2015) demonstraram empiricamente que as práticas de divulgação dos relatórios de responsabilidade social corporativa não implicam em incrementos na qualidade geral do disclosure da firma, de modo que a divulgação desses relatórios constitui muito mais uma ação simbólica do que substantiva. Sob essa perspectiva, a publicação dos relatórios de sustentabilidade representaria apenas um custo adicional para a empresa.

Cabe mencionar que os estudos correlatos tratam a divulgação dos relatórios não financeiros com conteúdo informacional relacionado às questões socioambientais de modo genérico, isto é, não fazem distinção na amostra entre os diferentes tipos de relatório, como relatório de responsabilidade social corporativa (RSC), relatório integrado, relatório da administração, relatório de sustentabilidade, entre outros. Por exemplo, Rover, Tomazzia, Murcia e Borba (2012) consideraram demonstrações financeiras padronizadas e relatórios de sustentabilidade para estudar os determinantes da divulgação ambiental de caráter voluntário; Michelon et al. (2015) incluíram na amostra relatórios de RSC, relatórios de sustentabilidade e relatórios anuais das firmas para avaliar a qualidade geral do disclosure; Stolowy e Paugam (2018) abordaram os relatórios de RSC e de sustentabilidade para discutir o aumento das publicações socioambientais de caráter voluntário pelas firmas. Sendo assim, observa-se uma lacuna na literatura, a qual este trabalho se propõe a preencher, quanto às contribuições específicas de cada relatório publicado para performance das firmas, neste caso, o relatório de sustentabilidade.

Ademais, não se tem claro qual a associação entre a publicação do relatório de sustentabilidade (ou similar) e o desempenho das empresas. Por um lado, a firma pode incorrer em custos adicionais com o processamento e a divulgação dos relatórios de sustentabilidade, bem como com as próprias ações e atividades socioambientais apresentadas nesses documentos, as quais tendem a comprometer a performance. Por outro lado, as empresas podem se beneficiar da publicação desses relatórios, já que a transparência dos aspectos socioambientais favorece a percepção que investidores, consumidores, fornecedores e outros públicos de interesse têm sobre a organização, com implicações positivas para o desempenho. Assim, entende-se que esse tema ainda carece de maiores evidências, o que motivou o desenvolvimento desta pesquisa, conduzida a partir da seguinte questão: qual a associação entre a publicação do relatório de sustentabilidade e o desempenho das empresas abertas brasileiras?

Portanto, este trabalho tem como objetivo geral analisar a associação entre a publicação do relatório de sustentabilidade e o desempenho das empresas abertas brasileiras. Para atingir o objetivo geral, enumeram-se os seguintes objetivos específicos: i) coletar dados na base Economatica referentes às características da firma, bem como nos relatórios Relate ou Explique divulgados pela B3 no que se refere à lista de empresas que divulgam relatórios de sustentabilidade; ii) utilizar técnicas estatísticas (estatísticas descritivas, testes de diferença de média e correlação) para análise dos dados coletados.

\section{REVISÃO DA LITERATURA}

Segundo Laskar (2018), o objetivo da sustentabilidade consiste em manter a solidariedade social, conservar o meio ambiente e assegurar o desenvolvimento econômico de forma balanceada. Com a crescente preocupação da sociedade com questões sociais, ambientais e econômicas, as firmas são pressionadas por seus stakeholders a apresentar bom desempenho nessas três dimensões, de modo que o relatório de sustentabilidade constitui o meio pelo qual esse desempenho é comunicado. Diante disso, nesta seção serão abordados estudos que examinaram os determinantes da divulgação de aspectos socioambientais, envolvendo assuntos como rentabilidade, governança corporativa, custo de capital, gerenciamento de resultados, entre outros. Os trabalhos foram selecionados por meio de buscas na base Google Scholar pelas 
seguintes palavras-chave: contabilidade socioambiental, relatório de sustentabilidade e disclosure, nos idiomas português e inglês.

As organizações, ao adotarem uma postura socioambiental, o fazem a partir de diferentes motivações e fatores contextuais. Dentre as motivações, destacam-se: competitividade, isto é, a eventual possibilidade de obter vantagem competitiva sustentável e, consequentemente, incrementar a rentabilidade, proveniente de suas ações socioambientais; legitimação, a qual consiste na vontade da organização de adequar suas ações ao conjunto de normas, regulações, valores, crenças, entre outros aspectos intrínsecos ao ambiente em que está inserida; e, por fim, a responsabilidade ecológica, que faz a organização se preocupar com seus valores e obrigações com o bem-estar social. Deve-se mencionar que esses fatores motivacionais são influenciados por fatores contextuais, tais como: relevância da questão, ou seja, até que ponto determinado assunto ecológico possui significado para os stakeholders da organização; coesão do ambiente interorganizacional, que se refere à intensidade das interações e relações entre as organizações no ambiente; e preocupações individuais dos membros da organização com questões socioambientais (Bansal \& Roth, 2000).

Por sua vez, os motivos que levam as organizações a divulgar em seus relatórios anuais informações ambientais de caráter voluntário se relacionam a variáveis concernentes à governança corporativa, ao setor e ao país da organização. Halme e Huse (1997), ao examinarem dados de grandes organizações situadas em quatro diferentes países europeus (a saber, Finlândia, Noruega, Espanha e Suécia), encontraram evidências empíricas de que quanto maiores a dispersão da estrutura de propriedade e controle e o número de membros do conselho de administração, maior é a atenção da organização no sentido de divulgar informações ambientais nos relatórios. Os autores também constataram que as organizações de setores que desenvolvem operações que, por suas próprias características, degradam ou poluem o ambiente, bem como aquelas localizadas em países com parcela significante do Produto Interno Bruto (PIB) proveniente de atividades reconhecidamente poluidoras, apresentam informações ambientais mais completas e de melhor qualidade nos relatórios anuais.

De acordo com Dienes, Sassen e Fischer (2016), o comportamento das organizações no que se refere à publicação do relatório de sustentabilidade depende dos requerimentos exigidos pelo ambiente corporativo e ambiental em que a empresa está inserida. Por exemplo, para firmas que estão diretamente envolvidas com questões ambientais em função de suas operações, a publicação do relatório de sustentabilidade pode configurar uma atividade comum, uma vez que a divulgação do desempenho sustentável, nesses casos, tende a ser uma prática do setor e uma expectativa da sociedade. Vale ressaltar que Dienes et al. (2016) ainda indicaram algumas variáveis direcionadoras da publicação do relatório de sustentabilidade, dentre as quais destacam-se: estrutura de capital, visibilidade da mídia e tamanho da firma.

Nesse contexto, Stolowy e Paugam (2018) afirmam que nas últimas décadas houve um aumento significativo no número de relatórios não financeiros publicados pelas organizações. Para fundamentar tal afirmação, os autores indicaram dados segundo os quais o percentual de firmas listadas nos dois principais índices de ações da Europa e dos Estados Unidos, no período de 2002 a 2015, que publicaram relatórios de sustentabilidade ou de responsabilidade social corporativa passou de aproximadamente 5\% para 77\%. O ano de 2007 foi quando se observaram maiores mudanças no que se refere à publicação desses relatórios, com a emissão das diretrizes do Global Reporting Initiative (GRI), de modo que de um ano para o outro o percentual de empresas que os divulgaram passou de $13 \%$ para $47 \%$.

Por outro lado, o fato de as organizações divulgarem informações socioambientais em seus relatórios não significa necessariamente alterações em seus processos, métodos e objetivos numa direção social ou ambientalmente responsável. Determinada firma pode divulgar relatórios socioambientais simplesmente para atender às expectativas sociais, nesse caso as questões sociais ou ambientais são modeladas de forma a se ajustarem aos objetivos corporativos previamente estabelecidos, e não o contrário. Isso também ocorre pelo fato de a estrutura de 
divulgação de informações das companhias ter como foco apresentar o desempenho econômicofinanceiro. De modo geral, diferentemente das informações financeiras, não existem normas específicas para a divulgação do desempenho socioambiental das organizações, ou mesmo para que auditores independentes possam avaliar os relatórios nesse sentido (Buhr, 2002).

A partir dessa perspectiva crítica dos relatórios de responsabilidade social corporativa, Michelon et al. (2015) estudaram elementos simbólicos e substantivos de três práticas de divulgação dos relatórios socioambientais de 112 firmas listadas na London Stock Exchange no período de 2005 a 2007, a saber: a publicação de um único relatório, o uso das diretrizes do GRI e a utilização de garantias para as informações publicadas, de forma a verificar se tais aspectos implicariam em maior qualidade do disclosure. Os resultados da pesquisa indicaram que as três práticas de divulgação dos relatórios de responsabilidade social corporativa não contribuem para incrementar a qualidade do disclosure. Isso quer dizer que a divulgação dos relatórios socioambientais tende a cumprir muito mais uma função simbólica do que substantiva.

A despeito disso, Magness (2006) demonstrou que, nas situações em que os stakeholders externos possuem poder para pressionar as organizações, as que adotam uma postura estratégica ativa apresentam melhores práticas de disclosure em termos de responsabilidade socioambiental. Para chegar a essa conclusão, Magness (2006) realizou análises de regressão considerando índices de disclosure e o número de comunicados de imprensa emitidos por empresas mineradoras de ouro do Canadá em 1995, ano em que ocorreu um acidente ambiental de grandes proporções na indústria de mineração canadense. Deste modo, os índices de disclosure constituíram uma medida para a divulgação de informações socioambientais nos relatórios contábil-financeiros, e os comunicados de imprensa corresponderam à postura estratégica da organização quanto à demanda dos stakeholders externos por informações a respeito do desastre ambiental e suas implicações para a organização. Os resultados dos testes indicaram uma relação positiva entre emissão de comunicados de imprensa e disclosure.

O disclosure das atividades de responsabilidade social corporativa pode também exercer efeito positivo sobre o custo de capital. Isso foi o que concluíram Dhaliwal, Li, Tsang e Yang (2011) após analisarem dados relativos a 213 empresas norte-americanas no período de 1993 a 2007. A partir da revisão da literatura, os autores teorizaram que, se a divulgação das práticas de responsabilidade social corporativa da organização pode contribuir para reduzir o custo de capital, as firmas teriam, portanto, incentivos para divulgar tais informações nos seus relatórios, especialmente aquelas com elevado custo de capital. Além disso, a divulgação das atividades de responsabilidade social corporativa implicaria na diminuição desse custo. Ao testarem essas hipóteses, Dhaliwal et al. (2011) encontraram evidências empíricas de que o custo de capital da organização no ano anterior está positivamente associado ao disclosure de informações de responsabilidade social no ano subsequente. Do mesmo modo, os achados sugeriram que a divulgação dessas informações, de fato, está associada à posterior redução do custo de capital.

Fatemi, Glaum e Kaiser (2017) investigaram a relação entre as forças e fraquezas de uma organização no tocante aos fatores sociais, ambientais e de governança e o valor da firma, bem como o efeito moderador do disclosure desses elementos na mencionada relação. A partir da análise de dados de 403 empresas norte-americanas no período de 2006 a 2011 (totalizando 1.640 observações), os autores encontraram evidências de que boas práticas sociais, ambientais e de governança adotadas pela organização implicam no aumento do valor da firma, enquanto as más condutas nesse sentido o comprometem, diminuindo-o. O efeito do disclosure na relação demonstrou variar conforme a conduta da organização. Quando a firma possui fortes práticas sociais, ambientais e de governança, a divulgação desses elementos enfraquece sua relação com o valor. A possível justificativa para esse achado se fundamenta no fato de que o mercado poderia interpretar a divulgação dos fatores sociais, ambientais e de governança como uma maneira de justificar investimentos excessivos nessas atividades. Por outro lado, nos casos em que tais práticas são fracas, o disclosure desses elementos exerce efeito positivo sobre o valor. Fatemi et al. (2017) argumentam que isso pode ocorrer em função de o disclosure colaborar para 
a legitimação do comportamento negativo da firma quanto a esses aspectos, explicando assim aos investidores as consequências das operações e políticas da empresa, ou mesmo por conta da maior credibilidade proporcionada pela divulgação dessas informações.

Sun, Salama, Hussainey e Habbash (2010) examinaram se o gerenciamento de resultados com base em accruals discricionários exerce algum efeito no disclosure das práticas corporativas ambientais, bem como o impacto de mecanismos de governança corporativa nessa relação. A amostra do estudo contou com dados de 245 empresas não financeiras britânicas no ano de 2007, os quais foram analisados a partir de regressões estimadas pelo método dos mínimos quadrados ordinários com erros padrões robustos. Dentre os resultados encontrados por Sun et al. (2010), a associação entre disclosure ambiental e gerenciamento de resultados não se mostrou estatisticamente significativa. Apesar disso, ao considerarem os mecanismos de governança corporativa, especificamente o tamanho do conselho de administração e a diligência do comitê de auditoria, os autores encontraram evidências de que a relação entre disclosure ambiental e gerenciamento de resultados é afetada pela diligência do comitê de auditoria.

Em um trabalho mais amplo, Martínez-Ferrero, Garcia-Sanchez e Cuadrado-Ballesteros (2013) estudaram 747 empresas não financeiras de 25 países, no período entre 2002 e 2010, com o objetivo de examinar a relação entre qualidade da informação financeira e divulgação de informações de responsabilidade social corporativa. Além do gerenciamento de resultados utilizado por Sun et al. (2010), Martínez-Ferrero et al. (2013) consideraram ainda o conservadorismo contábil e a qualidade dos accruals (modelos de Dechow-Dichev e de BallShivakumar) como proxies para a qualidade da informação contábil-financeira. De maneira geral, os resultados da pesquisa sugeriram a existência de uma relação positiva e estatisticamente significativa entre a qualidade da informação contábil-financeira e o disclosure socioambiental voluntário. Isso significa que a qualidade das informações contábil-financeiras contidas nos relatórios financeiros das organizações afeta de modo positivo o grau de divulgação de aspectos socioambientais.

O estudo de Baldini, Maso, Liberatore, Mazzi e Terzani (2018), com dados de firmas de diversos países no período de 2005 a 2012, demonstrou que as práticas de disclosure socioambiental são afetadas por características da organização e aspectos nacionais. Dentre os resultados da referida pesquisa destaca-se que, no país, a corrupção apresentou relação negativa com o disclosure socioambiental. A justificativa para esse achado foi que as organizações que fazem uso de práticas antiéticas tenderiam a não as divulgar. Por sua vez, a taxa de desemprego se mostrou positivamente relacionada ao disclosure socioambiental. Os autores argumentaram que a divulgação poderia ser utilizada como um mecanismo para atrair possíveis bons empregados, tendo em vista que pessoas que buscam boas oportunidades de carreira considerariam informações socioambientais ao escolherem a firma para trabalhar. Quanto às características da firma, de modo geral, se mostraram positivamente relacionadas ao disclosure socioambiental. Essas variáveis abrangeram alavancagem, tamanho, rentabilidade, cobertura dos analistas, entre outras.

No que se refere às evidências indicadas na literatura brasileira, Braga, Oliveira e Salotti (2009) avaliaram a influência de determinadas variáveis, dentre as quais se destacam o tamanho da firma, o desempenho e o endividamento, quanto à divulgação ambiental nas demonstrações contábeis de empresas brasileiras. A partir de dados provenientes de uma amostra composta por 108 empresas classificadas no ranking da revista Exame Melhores e Maiores de 2007 com ações listadas na B3, Braga et al. (2009) indicaram evidências empíricas de que o tamanho da firma, a riqueza gerada e o setor de atividade influenciam diretamente o nível de divulgação ambiental. Por outro lado, algumas variáveis, como desempenho e endividamento, não demonstraram exercer efeito estatisticamente significativo no disclosure ambiental.

Em pesquisa similar, Rover et al. (2012) estudaram os fatores determinantes da divulgação ambiental de caráter voluntário de empresas brasileiras consideradas potencialmente poluidoras. A amostra do trabalho contou com empresas de capital aberto com ações listadas na 
B3 que exerciam atividades econômicas de alto impacto ambiental e que publicaram Demonstrações Financeiras Padronizadas ou Relatórios de Sustentabilidade no período de 2005 a 2007, totalizando 57 firmas. Dentre as conjecturas iniciais levantadas no artigo, Rover et al. (2012) hipotetizaram que empresas maiores, com melhores índices de retorno sobre o ativo e com maior endividamento divulgariam mais informações ambientais. Contudo, os resultados da pesquisa corroboraram apenas a suposição de uma relação positiva entre tamanho da firma e divulgação ambiental. Os resultados para a relação da rentabilidade e do endividamento com o disclosure ambiental se mostraram inconclusivos.

Por sua vez, Conceição, Dourado, Baqueiro, Freire e Brito (2011) investigaram o nível de divulgação do desempenho de RSC, bem como sua relação com o desempenho econômicofinanceiro e social, por meio de dados provenientes de demonstrações financeiras das empresas brasileiras listadas na Bovespa. A partir das análises realizadas, os autores encontraram evidências empíricas de que o disclosure de elementos da RSC é determinado fundamentalmente pelo desempenho econômico-financeiro e social, isso no caso das firmas da amostra que exerciam atividades não regulamentadas (não normatizadas e fiscalizadas por agências reguladoras); para as firmas regulamentadas os resultados nesse sentido foram inconclusivos.

Calixto (2013) realizou uma análise de conteúdo das informações socioambientais publicadas por 226 empresas latino-americanas, a partir de dados coletados no período de 2004 a 2009, com o objetivo de analisar as informações socioambientais nos relatórios e estabelecer comparações entre firmas de diferentes países. Os achados do estudo mostraram que grande parte das firmas estudadas não disponibilizaram informações socioambientais relevantes nos seus relatórios publicados, sendo as firmas brasileiras as que apresentaram maiores níveis de divulgação nesse sentido. Dentre os veículos utilizados para apresentar informações socioambientais, o relatório anual configurou-se como o principal canal, seguido pelo relatório de sustentabilidade.

Diante do exposto, observa-se que as evidências concernentes aos benefícios da divulgação socioambiental são mistas. Por um lado, trabalhos como os de Dhaliwal et al. (2011), Martínez-Ferrero et al. (2013), Baldini et al. (2018) sugerem que a publicação de relatórios com conteúdo socioambiental está relacionada a melhor qualidade da informação contábil-financeira, menor custo de capital e maior rentabilidade. Por outro lado, existem estudos inconclusivos quanto às vantagens para o desempenho da firma com a publicação dos relatórios, como apontam Braga et al. (2009), Rover et al. (2012) e Michelon et al. (2015). Assim, esta pesquisa contribui ao fornecer evidências adicionais da associação entre a publicação do relatório de sustentabilidade e o desempenho das empresas abertas brasileiras. Este trabalho também avança em relação aos demais ao propor uma análise específica do relatório de sustentabilidade, uma vez que quando se considera na amostra diferentes publicações, não se pode precisar os efeitos da divulgação socioambiental provenientes de cada tipo de relatório.

\section{METODOLOGIA}

Diante do objetivo de analisar a associação entre a publicação do relatório de sustentabilidade e o desempenho das empresas abertas brasileiras, este estudo pode ser classificado como uma pesquisa descritiva. Conforme Gil (2002), as pesquisas descritivas possuem como finalidade principal descrever as características de fenômenos ou populações, até mesmo estabelecer relações entre variáveis. Além disso, dentre os principais aspectos que envolvem esse tipo de pesquisa está o uso de técnicas padronizadas de coletadas de dados.

Quanto à abordagem do problema, este estudo se caracteriza como uma pesquisa de abordagem quantitativa, visto que foram empregados instrumentos estatísticos com o intuito de atingir alguma representatividade numérica. Tal entendimento está em concordância com Fonseca (2002), para quem a pesquisa de abordagem quantitativa é aquela cujos resultados podem ser quantificados, além de pressupor que constituem uma representação real de toda a 
população-alvo, uma vez que normalmente as amostras são grandes e consideradas representativas da população. Fonseca (2002) ainda menciona que a pesquisa quantitativa faz uso da linguagem matemática para descrever as relações entre variáveis ou causas de um fenômeno.

No que se refere à coleta de dados, foram levantados dados sobre a publicação do relatório de sustentabilidade das empresas abertas brasileiras listadas na B3, os quais foram disponibilizados no relatório "Relate ou Explique" da própria bolsa, no período de 2012 a 2016. Além disso, utilizou-se a base Economatica para coletar dados referentes ao desempenho das firmas analisadas (mensurado pelo retorno sobre o ativo), bem como de outras variáveis, as quais Braga et al. (2009), Rover et al. (2012), Dienes et al. (2016) e outros autores citados no decorrer deste trabalho demonstraram ser direcionadoras da publicação do relatório de sustentabilidade ou divulgação de informações ambientais, a saber: tamanho da firma (mensurado pelo logaritmo natural do ativo total) e estrutura de capital (mensurada pelo debt-to-equity ratio).

Assim, a amostra do estudo contou com todas as empresas abertas brasileiras listadas na B3, exceto as financeiras, por suas especificidades contábeis, com dados disponíveis no período de 2012 a 2016, as quais totalizaram 1.889 observações. O período da amostra foi escolhido em função da disponibilidade do banco de dados das respostas das empresas referentes à iniciativa "Relate ou Explique para Relatório de Sustentabilidade ou Integrado", realizada pela B3 em parceria com a Global Reporting Initiative (GRI).

Para a análise dos dados coletados, utilizou-se o método estatístico. Segundo Gil (2008), esse método se baseia na aplicação da teoria da probabilidade, representando um importante auxílio para a investigação nas pesquisas sociais. O autor ainda afirma que o método estatístico é bastante aceito por parte dos pesquisadores com preocupações de cunho quantitativo, uma vez que as explicações advindas dele possuem boa probabilidade de acerto e razoável grau de precisão. Dentre as técnicas estatísticas utilizadas neste trabalho, destacam-se medidas descritivas (média, desvio-padrão, mínimo e máximo), testes de diferenças de média e análise de correlação.

Por fim, deve-se mencionar os tratamentos e testes que fundamentaram as escolhas estatísticas neste estudo. Inicialmente, com o intuito de tratar os outliers, as variáveis foram "winsorizadas" (o valor considerado para o procedimento de winsorize foi de 0,025). Além disso, para verificar a homocedasticidade, utilizou-se o teste de Levene, o qual identificou heterocedasticidade nas variáveis do estudo. Assim, o teste t para a diferença de médias foi feito supondo variâncias desiguais. Do mesmo modo, para a análise de correlação entre as variáveis, na ausência de homocedasticidade, utilizou-se o coeficiente de correlação por postos de Spearman. Os testes foram realizados com auxílio do software Stata versão 13.

\section{RESULTADOS}

A Tabela 1 apresenta as estatísticas descritivas (média, desvio-padrão, mínimo e máximo) para as variáveis em estudo. O número de observações para as empresas no período de 2012 a 2016 totalizou 1.889. Dentre as empresas da amostra, verificou-se que 31,5\% apresentaram relatório de sustentabilidade. Quanto à rentabilidade, o retorno sobre o ativo das firmas teve média de $-19,85 \%$. A média para a variável tamanho, mensurada pelo logaritmo natural do ativo, foi de aproximadamente 13,88. Por fim, o debt-to-equity ratio das firmas, em média, foi de 1,80. 
Tabela 1

Estatísticas descritivas para as variáveis em estudo

\begin{tabular}{lccccc}
\hline Variável & \# obs. & Média & D.P. & Min. & Max. \\
\hline sust & 1.889 & 0,3150 & 0,4646 & 0 & 1 \\
roa & 1.889 & $-0,1985$ & 0,8457 & $-4,6377$ & 0,2149 \\
lnatv & 1.889 & 13,8834 & 2,9116 & 4,4062 & 17,9731 \\
alav & 1.889 & 1,8005 & 3,4307 & $-5,4900$ & 14,4038 \\
\hline
\end{tabular}

Nota. sust = variável dummy para divulgação do relatório de sustentabilidade, recebendo valor 1 quando a empresa divulga o relatório de sustentabilidade e valor 0 nos demais casos; roa = representa o retorno sobre o ativo, obtido a partir da razão entre o lucro líquido e o total do ativo; lnatv = representa o tamanho da empresa, obtido a partir do logaritmo natural do ativo total; alav = representa a alavancagem financeira, obtida a partir do debt-to-equity ratio.

Conforme indicado na Tabela 2, as empresas da amostra que publicaram relatório de sustentabilidade apresentaram média de retorno sobre o ativo superior às demais, sendo a média de $3,11 \%$ para as firmas que divulgaram o relatório de sustentabilidade e $-30,40 \%$ para as outras. De maneira similar, as médias para alavancagem financeira e tamanho foram maiores para as firmas que publicaram relatório de sustentabilidade. Vale ressaltar que as diferenças de médias para essas variáveis (retorno sobre o ativo, tamanho e alavancagem financeira) entre os grupos de firmas que divulgaram o relatório de sustentabilidade e as demais foram estatisticamente significativas ao nível de $1 \%$.

Tabela 2

Diferenças de média entre as firmas que publicam e que não publicam relatório de sustentabilidade

\begin{tabular}{|c|c|c|c|c|c|c|}
\hline Variável & \# obs. & Média & erro & D.P. & $\mathbf{t}$ & sig. \\
\hline \multicolumn{7}{|l|}{ roa } \\
\hline sust $=0$ & 1.294 & $-0,3040$ & 0,0279 & 1,0026 & \multirow{2}{*}{$-11,9200$} & \multirow{2}{*}{0,0000} \\
\hline sust $=1$ & 595 & 0,0311 & 0,0037 & 0,0899 & & \\
\hline \multicolumn{7}{|l|}{ lnatv } \\
\hline sust $=0$ & 1.294 & 13,0280 & 0,0837 & 3,0102 & \multirow{2}{*}{$-26,3301$} & \multirow{2}{*}{0,0000} \\
\hline sust $=1$ & 595 & 15.7435 & 0,0603 & 1,4704 & & \\
\hline \multicolumn{7}{|l|}{ alav } \\
\hline sust $=0$ & 1.294 & 1,6009 & 0,0987 & 3,5509 & \multirow{2}{*}{$-3,9293$} & \multirow{2}{*}{0,0001} \\
\hline sust $=1$ & 595 & 2,2347 & 0,1276 & 3,1126 & & \\
\hline
\end{tabular}

Nota. sust = variável dummy para divulgação do relatório de sustentabilidade, recebendo valor 1 quando a empresa divulga o relatório de sustentabilidade e valor 0 nos demais casos; roa = representa o retorno sobre o ativo, obtido a partir da razão entre o lucro líquido e o total do ativo; lnatv = representa o tamanho da empresa, obtido a partir do logaritmo natural do ativo total; alav = representa a alavancagem financeira, obtida a partir do debt-to-equity ratio. Como o teste de Levene indicou a existência de heterocedasticidade, utilizou-se o teste t para diferença entre médias supondo variâncias desiguais.

Na Tabela 3, o coeficiente de correlação de Spearman para a relação entre a publicação do relatório de sustentabilidade e o retorno sobre o ativo foi de 0,2341 . Isso sugere que, apesar de fraca, existe uma associação positiva entre essas variáveis. Do mesmo modo, o tamanho da firma e a alavancagem estão positivamente associados à publicação do relatório de sustentabilidade, com coeficientes de 0,4971 e 0,1874, respectivamente. Assim, pode-se afirmar que, conforme aumentam o desempenho, o tamanho e a alavancagem da firma, eleva-se a ocorrência da publicação do relatório de sustentabilidade. Apesar disso, deve-se mencionar que não se trata de uma relação causal, isto é, alterações em uma variável não causam necessariamente mudanças em outra. 
Tabela 3

\section{Matriz de correlação para as variáveis em estudo}

\begin{tabular}{lccccc}
\hline Variável & $\#$ obs. & sust & roa & lnatv & alav \\
\hline sust & 1.889 & 1,0000 & & & \\
roa & 1.889 & $0,2341^{*}$ & 1,0000 & & \\
lnatv & 1.889 & $0,4971^{*}$ & $0,2504^{*}$ & 1,0000 & 1,0000 \\
alav & 1.889 & $0,1874^{*}$ & $0,0894^{*}$ & $0,4627^{*}$ &
\end{tabular}

Nota. sust = variável dummy para divulgação do relatório de sustentabilidade, recebendo valor 1 quando a empresa divulga 0 relatório de sustentabilidade e valor 0 nos demais casos; roa = representa o retorno sobre o ativo, obtido a partir da razão entre o lucro líquido e o total do ativo; lnatv = representa o tamanho da empresa, obtido a partir do logaritmo natural do ativo total; alav = representa a alavancagem financeira, obtida a partir do debt-to-equity ratio. Como o teste de Levene indicou a existência de heterocedasticidade, utilizou-se o coeficiente de correlação por postos de Spearman. * significante ao nível de $1 \%$.

Diante destes resultados, pode-se afirmar que, em média, as firmas com desempenho superior, as quais são maiores em termos de ativo total e alavancadas financeiramente, estão mais propensas a publicar relatórios de sustentabilidade. Uma explicação plausível para esses achados se fundamenta no fato de que empresas grandes, rentáveis e alavancadas tendem a dispor de maiores recursos para empregar na publicação de relatórios de caráter voluntário, como o relatório de sustentabilidade.

Deve-se mencionar ainda que as evidências registradas neste estudo corroboram argumentos apresentados em pesquisas correlatas anteriores no que se refere à associação positiva entre desempenho da firma e relatório de sustentabilidade, bem como dos demais direcionadores da publicação desse relatório aqui contemplados (tamanho da firma e alavancagem financeira). Algumas dessas pesquisas são de: Jones et al. (2007), sobre a associação entre o relatório de sustentabilidade e uma série de atributos de desempenho financeiro e de mercado de firmas australianas; Braga et al. (2009), quanto à influência do tamanho da firma no disclosure ambiental; Baldini et al. (2018), sobre os determinantes da firma e do país no disclosure socioambiental; dentre outros estudos abordados no decorrer deste artigo.

\section{CONCLUSÃO}

Este trabalho teve como objetivo analisar a associação entre a publicação do relatório de sustentabilidade e o desempenho das empresas abertas brasileiras. Foram coletados dados sobre a publicação do relatório de sustentabilidade das empresas abertas brasileiras listadas na B3, disponibilizados no relatório "Relate ou Explique" da própria bolsa. Os dados para as demais variáveis sobre as características da firma, como desempenho, tamanho e alavancagem, foram coletados a partir da base Economatica. Assim, a amostra do estudo contou com todas as empresas abertas brasileiras listadas na B3, exceto as financeiras, por suas especificidades contábeis, com dados disponíveis no período de 2012 a 2016, as quais totalizaram 1.889 observações.

Dentre os resultados, observou-se que as empresas que publicam relatório de sustentabilidade possuem médias superiores no que se refere às medidas para desempenho (retorno sobre o ativo), tamanho (logaritmo natural do ativo) e alavancagem financeira (debt-toequity ratio) em relação às firmas que não publicam tal documento. Essa diferença foi estatisticamente significativa. Além disso, os coeficientes de correlação de Spearman para as variáveis estudadas, dentre outros aspectos, indicaram uma associação positiva e estatisticamente significativa entre a publicação do relatório de sustentabilidade e o desempenho, tamanho e alavancagem da firma.

Entende-se que os achados registrados nesta pesquisa podem contribuir para a literatura e para o avanço dos estudos sobre o tema. Primeiro, este trabalho apresenta novas evidências relativas ao mercado brasileiro no que se refere aos principais direcionadores da publicação do 
relatório de sustentabilidade (desempenho, tamanho da firma e estrutura de capital), amplamente indicados em pesquisas internacionais. Além disso, a partir dos resultados apresentados, pode-se identificar o perfil e as características fundamentais das firmas que estão mais propensas a divulgar o relatório de sustentabilidade, de modo a suscitar discussões a respeito das publicações de caráter voluntário pelas firmas brasileiras.

Apesar das contribuições desta pesquisa, algumas limitações devem ser mencionadas. Para a classificação das empresas quanto à publicação do relatório de sustentabilidade, utilizaram-se as respostas das firmas indicadas no documento "Relate ou Explique para Relatório de Sustentabilidade ou Integrado", de iniciativa da B3. Por isso, o fato de determinada empresa não se manifestar no "Relate ou Explique" não significa necessariamente que ela não publicou relatório de sustentabilidade no período. Ademais, as firmas podem divulgar informações de cunho socioambiental de outras maneiras, como no relatório anual ou mesmo no relatório da administração, os quais não foram contemplados nesta pesquisa.

Para estudos futuros, sugere-se analisar a qualidade das informações publicadas nos relatórios de sustentabilidade, isto é, verificar se de fato os aspectos socioambientais divulgados são relevantes para os stakeholders das empresas. Além disso, a fim de ampliar os resultados deste estudo, recomenda-se sua replicação com diferentes medidas daquelas aqui utilizadas para o desempenho, tamanho e estrutura de capital das firmas. Por fim, utilizar amostras com empresas de outros países pode contribuir para compreender os direcionadores da publicação do relatório de sustentabilidade nos mercados exteriores.

\section{REFERENCIAS}

Baldini, M., Maso, L. D., Liberatore, G., Mazzi, F., \& Terzani, S. (2018). Role of country and firm-level determinants in environmental, social, and governance disclosure. Journal of Business Ethics, 150(1), 79-98.

Bansal, P., \& Roth, K. (2000). Why companies go green: a model of ecological responsiveness. Academy of Management Journal, 43(4), 717-736.

BM\&FBovespa. (2016). Relate ou Explique para Relatório de Sustentabilidade ou Integrado: um case brasileiro de sucesso. BM\&FBovespa, 2016. Recuperado em 28 julho, 2018, de http://www.bmfbovespa.com.br/pt_br/institucional/sustentabilidade/nas-empresas/relateou-explique/

Braga, J. P., Oliveira, J. R. S., \& Salotti, B. M. (2009). Determinants of Level of Environmental Disclosure in the financial statements of Brazilian Companies. Revista de Contabilidade da UFBA, 3(3), 81-95.

Buhr, N. (2002). A structuration view on the initiation of environmental reports. Critical Perspectives on Accounting, 13(1), 17-38.

Calixto, L. A. (2013). A divulgação de relatórios de sustentabilidade na América Latina: um estudo comparativo. Revista de Administração, 48(4), 828-842.

Conceição, S. H., Dourado, G. B., Baqueiro, A. G., Freire, S., \& Brito, P. C. (2011). Fatores determinantes no disclosure em Responsabilidade Social Corporativa (RSC): um estudo qualitativo e quantitativo com empresas listadas na Bovespa. Gestão \& Produção, 18(3), 461-472. 
Dhaliwal, D. S., Li, O. Z., Tsang, A., \& Yang, Y. G. (2011). Voluntary Nonfinancial Disclosure and the Cost of Equity Capital: The Initiation of Corporate Social Responsibility Reporting. The Accounting Review, 86(1), 59-100.

Dienes, D., Sassen, R., \& Fischer, J. (2016). What are the drivers of sustainability reporting? A systematic review. Sustainability Accounting, Management and Policy Journal, 7(2), 154189.

European Sustainable Investment Forum. (2014). European SRI Study 2014. Belgium.

Fatemi, A., Glaum, M., \& Kaiser, S. (2017). ESG performance and firm value: The moderating role of disclosure. Global Finance Journal, In Press.

Fonseca, J. J. S. (2002). Metodologia da pesquisa científica. Fortaleza: UEC.

Gil, A. C. (2002). Como Elaborar Projetos de Pesquisa (4a ed.). São Paulo: Atlas.

Gil, A. C. (2008). Métodos e Técnicas de Pesquisa Social (6a ed.). São Paulo: Atlas.

Gray, R., \& Milne, M. J. (2002). Sustainability Reporting: Who's Kidding Whom?. Accountability Transparency Sustainability, 1-5.

Halme, M., \& Huse, M. (1997). The influence of corporate governance, industry and country factors on environmental reporting. Scandinavian Journal of Management, 13(2), 137-157.

Jones, S., Frost, G., Loftus, J., \& Van Der Laan, S. (2007). An Empirical Examination of the Market Returns and Financial Performance of Entities Engaged in Sustainability Reporting. Australian Accounting Review, 17(41), 78-87.

Laskar, N. Impact of corporate sustainability reporting on firm performance: an empirical examination in Asia. (2018). Journal of Asia Business Studies, 12(4), 571-593.

Magness, V. (2006). Strategic posture, financial performance and environmental disclosure: an empirical test of legitimacy theory. Accounting, Auditing \& Accountability Journal, 19(4), $540-563$.

Martínez-Ferrero, J., Garcia-Sanchez, I. M., \& Cuadrado-Ballesteros, B. (2015). Effect of Financial Reporting Quality on Sustainability Information Disclosure. Corporate Social Responsibility and Environmental Management, 22(1), 45-64.

McWilliams, A., \& Siegel, D. (2000). Corporate social responsibility and financial performance: correlation or misspecification?. Strategic Management Journal, 21(5), 603-609.

Michelon, G., Pilonato, S., \& Ricceri, F. (2015). CSR reporting practices and the quality of disclosure: An empirical analysis. Critical Perspectives on Accounting, 33(1), 59-78.

Rover, S., Tomazzia, E. C., Murcia, F. D., \& Borba, J. A. (2012). Explicações para a divulgação voluntária ambiental no Brasil utilizando a análise de regressão em painel. Revista de Administração, 47(2), 217-230. 
Stolowy, H., Paugam, L. (2018). The expansion of non-financial reporting: an exploratory. Accounting and Business Research, 48(5), 525-548.

Sun, N., Salama, A., Hussainey, K., \& Habbash, M. (2010). Corporate environmental disclosure, corporate governance and earnings management. Managerial Auditing Journal, 25(7), 679700 . 